\title{
LOVE STYLES FROM A BILINGUAL (HUNGARIAN-SERBIAN) AND A MONOLINGUAL (SERBIAN) PERSPECTIVE
}

\author{
Beata Grabovac \\ Teacher Training Faculty in Hungarian in Subotica, Subotica, Serbia \\ Budapest Faculty of Technology and Economics, Budapest, Hungary \\ E-mail: beagrabovac@gmail.com
}

\begin{abstract}
Recently there has been a growing body of research interested in the concept of love and in the emotional life of bilinguals. The aim of this research was twofold. One aim was to explore the love styles of young people in Vojvodina, Serbia in the context of Hungarian and Serbian language. On the other hand, a monolingual Serbian group and a bilingual group of Hungarian-Serbian young people were studied to see if there were significant differences in their intimate relationships in Serbian, as the dominant language and in Hungarian, as a minority language. The goal was to explore if there were different love styles connected to each language in a majority and a minority group. Additionally, we wanted to see if there were detectable language dominance effects in bilinguals, whether bilinguals had different romantic relationship constructs in their two languages.

In this research, Susan and Clyde Hendrick's Love Attitude Scale-Short form was applied. The scale was translated into Hungarian and Serbian. The equality of the meaning of the two scale versions was carefully matched.

The results showed that comparing the monolingual group and the bilingual group in the first language there were group differences in Eros and Agape. In the monolingual Hungarian and bilingual Serbian answers we can find the same differences: Eros and Agape were found to be more powerfully expressed in the bilingual group in both of their languages compared to the monolingual group. Considering bilinguals'first and second language results, two styles have been found to differ. These were Mania and Storge, which were present in different amounts in the first and the second language.

The relevance of this study lies in the fact that there is a rising number of multiethnic and multicultural intimate relationships. Many of the partners have to use a second language to express love and affection. Expression and understanding of emotions may depend on the language which is used in communication and on cultural variation in values and norms. This research has important implications for the study of ethnocultural differences and first- and second language modulated affective functioning.
\end{abstract}

Keywords: bilingualism, monolingualism, love, Love Attitude Scale, Hungarian, Serbian.

\section{Introduction}

Love schemas affect the way people think, feel and behave in their intimate relationships (Choo, Levine \& Hatfield, 1996). It is thus not surprising that the interest for love is present in many fields of psychology, with three branches emerging often: evolutionary psychology, personality psychology and cultural psychology. The evolutionary perspective emphasizes that the feeling of love serves the purpose of reproduction and is biologically determined. At the same time this phenomenon is seen as a social construct, with differences in love styles found between various ethnic groups (Schmitt, 2006). 
Theoretical approaches to love often aspire to give a full taxonomy of kinds of love. According to John Alan Lee (in Hendrick \& Hendrick, 2006) there are six basic love styles, which all produce Volume 4, 2012 different relationship behavior and outcomes, and different expectations. Lee found six basic styles of love: Eros, Ludus, Storge, Pragma, Mania and Agape. Today many researchers find this categorization a useful tool for investigating the concept of love and for making cross-cultural comparisons.

Hatfield, Rapson, Martel (in press) point to the fact that although passionate love is a universal feeling, it is nevertheless shaped by culture. The impact of the wider cultural environment and experience can be seen through the effects of ecological stress, which can change intimate behavior and affect love styles. According to Belsky (in Schmitt, 2006), stress, inadequate parenting and bad economic status all form a base for our later behavior in intimate relationships and generally do so in a negative way.

The question is how to obtain a good quality relationship? Clyde Hendrick and Susan Hendrick (Hendrick \& Hendrick, 2006) claim that for a relationship to last, it is important for the partners involved to have similar or the same love profiles. Regarding relationship prospects, they have found that the love style Eros, which is the most romantic and passionate love style with high levels of intimacy, relates positively to relationship satisfaction. In contrast, two other styles, Mania and Ludus, negatively affect relationship outcomes in the sense that it is very like that a relationship will end with these styles dominating in it. Mania can be characterized as a very possessive and dependable intimate behavior mixed with feelings of insecurity in the relationship. On the other hand, Ludus is the most inconstant style with no stability and serious intention in it, thus this style is frequently referred to as game-playing love.

\section{Problem of Research}

The aim of the research was to map and compare the love attitudes of two different ethnic groups in Vojvodina. A Serbian monolingual group and a Hungarian-Serbian bilingual group participated in the testing. The main aim was to explore if there are different love schemas attached to the two languages: the majority language, Serbian and a minority language, Hungarian. Another aim was to compare bilinguals' two languages, to see whether the same or different love styles are expressed through them.

One very broad initial hypothesis was that there will be some ethnic, majority-minority, grouprelated differences between Hungarian and Serbian. We assume that minority and majority group membership has an impact on personal and intimate attitudes through social power distribution, different norms and values and it is thus an important sociostructural variable (Sachdev \& Bourhis, 1991). These social effects presumably spread on individual personality traits through the feelings of belonging to one or the other group.

The second hypothesis was that bilinguals will manifest different emotional-behavioral style in their first and their second language. In the literature on bilingualism there is an ongoing debate about the emotionality of the first and second language (Pavlenko, 2005) and current inquiries are directed towards revealing the circumstances under which emotions and emotion-related words are more likely to be expressed and experienced in the first or in the second language and how the emotion lexicon is organized in bilingual people (Eilola, Havelka \& Sharma, 2007).

The third hypothesis was derived from the language factor: we assume that the Serbian answers in the monolingual group and the second language answers in the bilingual group will be very similar due to the "same language effects", which are assumed to have a role in transferring cultural norms and values.

\section{Research Focus}

In the past decades there has been growing interest for a cross-cultural comparison of love styles. Cultures differ in display rules and feeling rules, which furthermore regulate variation in spontaneity and emotional expression (Mesquita \& Frijda, 1992).

Searching for cultural differences, a line of studies was conducted to find out whether the individualist-collectivist dimension affects love concepts and schemas in different countries. The main 
distinction between these cultures is that individualistic cultures emphasize personal preferences, whereas collectivistic ones highlight group or family demands. Stemming from these differences in social requirements, there are variations in romantic behavior, too. In individualistic cultures, freedom of choice and romantic love are the most important values in life. In collectivistic cultures, there are some more traditional expectations and often the whole family has to give approval to a marriage with a chosen partner. In an earlier study conducted by Neto (2007) stable cross-cultural differences between British, Indian and Portuguese students were found in three love styles, Pragma, Mania and Agape. In this study, the Indian culture is claimed to be a collectivist culture as it displays more traditional values than the cultures of the participants from the two other countries.

The first aim of our study builds up on this line in an attempt to establish whether ethnic differences are connected to different romantic styles.

Another area of research deals with personality. It is an intriguing question how main personality dimensions are connected to intimate interpersonal relationships (White, Hendrick \& Hendrick, 2004). A research oriented towards finding the answer was conducted by White, Hendrick and Hendrick: they found that Neuroticism was positively connected to bad relationship quality, marital instability and generally, with negative relationship prospects. The love styles Mania and Ludus are found to be in a positive correlation with Neuroticism, while Storge correlates negatively with it. Storge is a love style which is characterized by stability and duration in interpersonal intimate relationships. On the other hand, Mania and Ludus are elusive styles, full of doubts, uncertainty and insecurity. Importantly, Mania completely mediates the relationship between Neuroticism and relationship satisfaction for females. White and his colleagues (2004) also found that Mania correlates positively with Neuroticism and impulsivity in females and that Neuroticism also correlates positively with Agape. Extraversion is found to positively correlate with Eros, the most romantic style.

Thus, on the individual level we can reveal a very complex picture of the relationship between personality structure and love schemas. The studies mentioned above decompose the phenomenon of love at different levels: culture-related studies on a more general level and personality related research on the individual level.

\section{Methodology of Research}

\section{General Background of Research}

For conducting the research, the short form of Clyde and Susan Hendrick's Love Attitudes Scale (Hendrick, Hendrick \& Dicke, 1998) was chosen, which features six subscales with four items in each subscale. According to Hatfield, Bensman, and Rapson (2011), this scale is among the three most popular scales nowadays that measure passionate love. For the purposes of the research, the scale was translated into Hungarian and Serbian. The testing took place in two high schools in Novi Sad and was done in groups of 15-20 young people. The bilingual group filled out first the Hungarian version and after a two-week period, the Serbian version of the scale.

\section{Sample of Research}

In the study, there was eighty one participant. The aim was to explore high school students who are in their adolescent period, intrigued by the theme of love. We assumed that first year university students are still inexperienced in the field of interpersonal relationships. The number of respondents/ subjects was constrained by extralinguistic factors. Namely, in Novi Sad in every school there is just one Hungarian class and several (e.g. 6-7) Serbian ones. In addition to this, Hungarian classes have significantly fewer pupils than Serbian ones, supposedly because of the minority status of the language and because there are Hungarian families/parents which/who choose to enroll their children to school in the dominant language. There were 47 Serbian monolingual and 34 Hungarian-Serbian bilingual participants. The monolingual group consisted of Serbian participants from the Grammar school "Svetozar Marković" in Novi Sad.

The mean age in the monolingual group was 16.531 (SD 0.504) with an age range between 
16-17 years. In the bilingual group the age range was between 16-19 years, with a mean age 17.03 (SD 0.937).

The bilingual group was composed of Hungarian-Serbian bilinguals from Novi Sad, from the Grammar school "Svetozar Marković" and from the Vocational secondary school "Bogdan Šuput".

The bilingual groups' bilingualism stems from social circumstances and this group fulfills Grosjean's criteria (Navracsics, 2007) for bilingualism: they can use both of their languages interchangeably in different situations in everyday life, with different people and talking about various topics, corresponding to their needs.

Novi Sad, the place of their wider social background is a multiethnic city, with Serbian as a dominant language and Hungarian as a minority language. In formal environments/situations people use Serbian, but in the minority group families, parents oftentimes send their children to school in Hungarian. These families often use Hungarian at home and in informal contexts. In a wider social environment however, the minority group uses the majority language. In formal learning environments this group learns Serbian as a second language. This way they frequently begin to learn a second language and get accustomed to it at a very early age. The schools in Novi Sad have Serbian and Hungarian classes in the same building, so the environment gives an opportunity to gain experience, to mix and to learn both languages.

\section{Instrument and Procedures}

Clyde and Susan Hendrick's (see Hendrick \& Hendrick, 1986 for the longer version) Love Attitudes Scale - Short Form was deemed a suitable instrument for the purposes of the research. There are 24 items in this abbreviated form, but the scale has adequate psychometric characteristics. There are six subscales with four items in each, covering the six love styles found by John Alan Lee (in Hendrick \& Hendrick, 2006): Eros, Ludus, Storge, Pragma, Mania and Agape. The translation procedure was the following: two Hungarian native speakers and two Serbian native speakers and one Hungarian-Serbian bilingual translated the English version of the scale into Hungarian and Serbian, respectively.

The research was conducted in two different high schools in Novi Sad, Serbia. It took 20-25 minutes to fill in the scale. The testing was done in groups of approximately 15-20 people. The bilingual group filled out the Hungarian version of the scale first. After a two week period, the Serbian version was administered to the bilingual group.

The rating scale used for answers was the following: A meant strong agreement with the statement, B meant moderate agreement, $\mathrm{C}$ was a neutral opinion, D meant moderate disagreement and E strong disagreement with the statement.

All the participants were instructed to give their answers with their actual lover in mind. For participants who were not in a relationship at the time of the research, the instruction was to think of their most recent partner. The instructions given to participants who had never been in a relationship was to give their answers imagining their ideal partner in a love relationship.

\section{Data Analysis}

The collected data were analyzed using SPSS 17. Independent sample t-tests were used to search for majority-minority group and Hungarian-Serbian language condition differences.

Firstly, a $\log 10$ transformation was applied to the raw data to satisfy the normality assumption of the t-tests. Language was an independent variable, the dependent variable was the scores on the six subscales of the Love Attitudes Scale-Short Form.

In the second analysis, a dependent sample t-test was used in order to see whether there were differences expressed between the bilinguals' first and second language emotionality and love schemas. 
OF PSYCHOLOGY

IN THE $21^{\text {st }}$ CENTURY Volume 4, 2012

\section{0 \\ Results of the Research}

Significant differences were found between the Hungarian group and the bilinguals' first language (Hungarian) answers. Eros and Agape were more intensively dominating the bilinguals' answers than the monolinguals' answers, comparing the dominant languages - Hungarian and Serbian, respectively (see Table 1. and Figure 1.).

Table 1. T-test for independent samples - monolingual Serbian group and bilingual Hungarian answers - significant differences.

\begin{tabular}{|c|c|c|c|c|c|c|}
\hline \multicolumn{7}{|c|}{ Independent Samples Test } \\
\hline $\begin{array}{l}\text { LOVE } \\
\text { STYLE }\end{array}$ & & t-test & df & $\begin{array}{l}\text { Significance } \\
\text { (2-tailed) }\end{array}$ & Mean & $\begin{array}{l}\text { Standard } \\
\text { deviation }\end{array}$ \\
\hline \multirow{2}{*}{ EROS (LOG) } & $\begin{array}{l}\text { Equal variances } \\
\text { assumed }\end{array}$ & -2.971 & 79 & 0.004 & 0.5385 & 0.11969 \\
\hline & $\begin{array}{l}\text { Equal variances } \\
\text { not assumed }\end{array}$ & -3.053 & 77.028 & 0.003 & 0.6136 & 0.10112 \\
\hline \multirow{2}{*}{$\begin{array}{l}\text { AGAPE } \\
\text { (LOG) }\end{array}$} & $\begin{array}{l}\text { Equal variances } \\
\text { assumed }\end{array}$ & -2.598 & 79 & 0.011 & 0.4005 & 0.19045 \\
\hline & $\begin{array}{l}\text { Equal } \\
\text { variances not } \\
\text { assumed }\end{array}$ & -2.737 & 78.999 & 0.008 & 0.5000 & 0.13676 \\
\hline
\end{tabular}

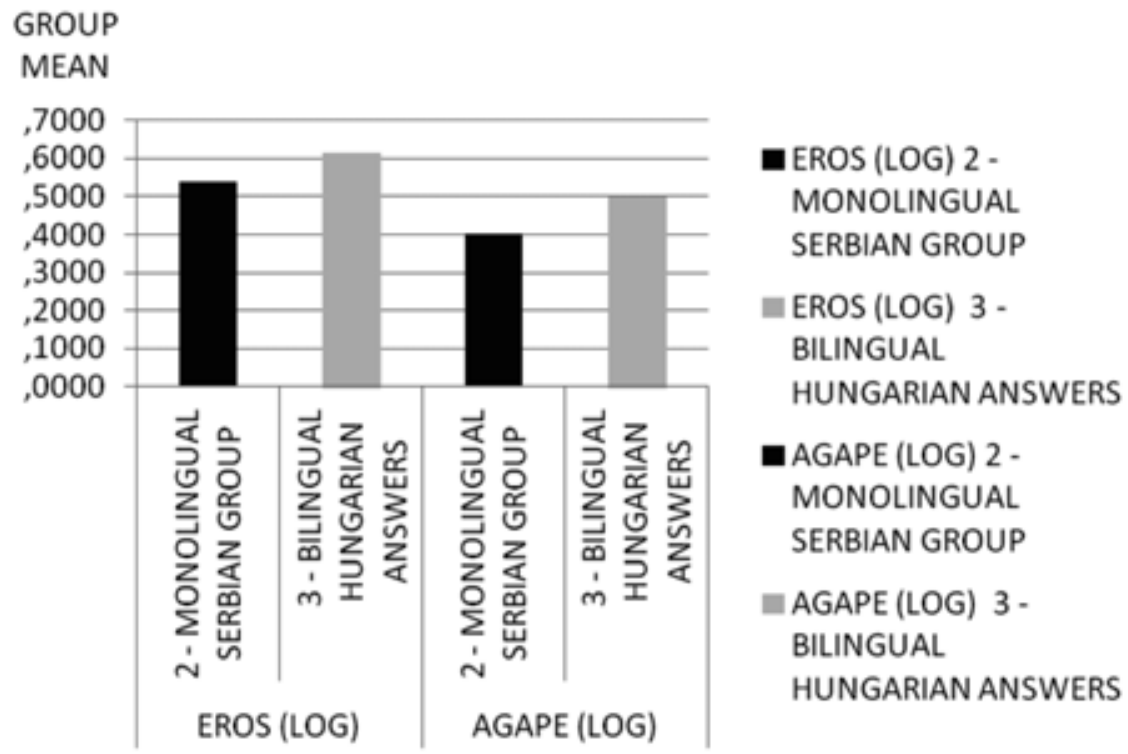

Figure 1: Comparison of love styles in the monolingual Serbian group and the bilingual Hungarian answers - significant differences. 
The second comparison concerned monolingual Serbian and bilingual Serbian answers. The bilingual respondents gave their answers in their second language in this part of the research. The same love styles were recognized here as in the first comparison and the same differences were noted: bilinguals were again more erotic and agapic than monolinguals (see Table 2 and Figure 2).

Table 2. T-test for independent samples - monolingual Serbian group and bilingual Serbian answers - significant differences.

\begin{tabular}{ccccccc}
\hline \multicolumn{7}{c}{ Independent Samples Test } \\
\hline $\begin{array}{c}\text { LOVE } \\
\text { STYLE }\end{array}$ & t-test & df & $\begin{array}{c}\text { Significance } \\
\text { (2-tailed) }\end{array}$ & Mean & $\begin{array}{c}\text { Standard } \\
\text { deviation }\end{array}$ \\
\hline & $\begin{array}{c}\text { Equal variances } \\
\text { assumed }\end{array}$ & -3.185 & 79 & 0.002 & 0.5385 & 0.11969 \\
EROS (LOG) & $\begin{array}{c}\text { Equal variances } \\
\text { not assumed }\end{array}$ & -3.395 & 78.431 & 0.001 & 0.6135 & 0.07897 \\
\hline & $\begin{array}{c}\text { Equal variances } \\
\text { assumed } \\
\text { AGAPE } \\
\text { (LOG) }\end{array}$ & -2.440 & 79 & 0.017 & 0.4005 & 0.19045 \\
& $\begin{array}{c}\text { Equal } \\
\text { variances not } \\
\text { assumed }\end{array}$ & -2.510 & 77.165 & 0.014 & 0.4985 & 0.15998 \\
\hline
\end{tabular}

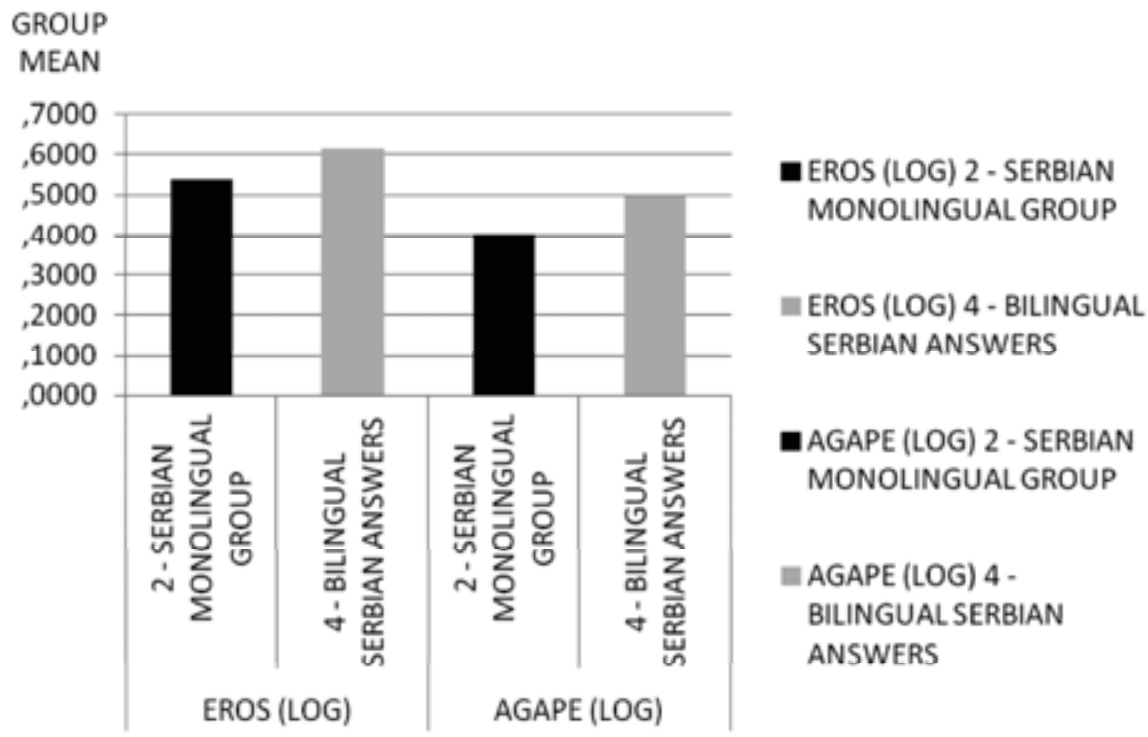

\section{Figure 2: Comparison of love styles in the monolingual Serbian group and the bilingual Serbian answers - significant differences.}

The third research aim was to see whether bilingual within subjects' answers differed depending on the language used when the first or the second language was evoked. A difference was found in the significance of Storge and Mania (see Table 3.). These styles had higher scores in the dominant, Hungarian language (see Figure 3.). 
Table 3. T-test for dependent samples - bilingual Hungarian answers and bilingual Serbian answers - tendency towards significance.

Paired Samples Test

\begin{tabular}{ccccc}
\hline LOVE STYLE & t-test & df & Significance (2-tailed) \\
\hline $\begin{array}{c}\text { Pair 3 } \\
\text { STORGE } \\
\begin{array}{c}\text { Pair 5 } \\
\text { MANIA }\end{array}\end{array}$ & $\begin{array}{c}\text { Storge Hungarian - Storge } \\
\text { Serbian (log) }\end{array}$ & 1.718 & 33 & 0.095 \\
\hline
\end{tabular}

Table 4. Means and standard deviations of the bilingual group - tendency towards significance.

\begin{tabular}{cccc}
\hline & & Mean & Standard deviation \\
\hline \multirow{2}{*}{ Pair 3 } & STORGE HUNGARIAN & 0.4353 & 0.16017 \\
& STORGE SERBIAN & 0.3868 & 0.21507 \\
\hline \multirow{2}{*}{ Pair 5} & MANIA HUNGARIAN & 0.4897 & 0.13561 \\
& MANIA SERBIAN & 0.4296 & 0.19020 \\
\hline
\end{tabular}

\begin{tabular}{|c|c|c|c|c|c|}
\hline \multicolumn{6}{|c|}{ GROUP } \\
\hline ,6000 & & & & & \\
\hline 4000 & & & & & \\
\hline 3000 & & & & & $\begin{array}{l}\text { - Pair } 3 \text { STORGE } \\
\text { HUNGARIAN }\end{array}$ \\
\hline 1000 & & & & & \\
\hline 10000, & & & & & - Pair 3 STORGE SERBIAN \\
\hline & & & & & \\
\hline & 峞 & क्षे & $\sum \stackrel{\mathrm{q}}{4}$ & $\bar{a}$ & $\begin{array}{l}\text { Pair } 5 \text { MANIA } \\
\text { HUNGARIAN }\end{array}$ \\
\hline & 况 & 嵌 & $\sum \underset{\text { I }}{\Sigma}$ & 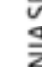 & - Pair 5 MANIA SERBIAN \\
\hline & & 佂 & & $\leq$ & \\
\hline & & & & & \\
\hline
\end{tabular}

Figure 3: Tendency towards significance between the two languages (Hungarian and Serbian) in the bilingual group.

\section{Discussion}

This exploratory study dealt with ethnic differences and monolingual-bilingual majority-minority group comparison. It was only the first step in mapping various language-social-cultural-love schema connections in Vojvodina.

Love schemas have been argued to be strongly influenced by early childhood experiences and are claimed to be shaped by later romantic experience (Choo, Levine \& Hatfield, 1996), thus they are dinamically changing over time. This research has shown that the language and culture factor could also have an altering-moderating effect on love styles. 
Pairwise comparisons of group means showed that different love styles dominated in HungarianSerbian and Serbian young people from Vojvodina. Two starting hypotheses were supported by the Volume 4, 2012 research and one was not. Namely, it was established that there are significant differences in love attitudes between the monolingual Serbian group and the bilinguals' first language. This is assumed to be due to some ethnic and slight cultural differences. The second question was whether there were differences between monolinguals and bilinguals in Serbian. Here, no definitive answers were reached, i.e. no overlapping pattern was found to exist, so the use of the same language between the minority and majority group did not yield the expected corresponding or overlapping answers.

Taking into consideration the bilingual subjects' answers, there were moderate differences in the answers in their first and their second language, implying that there might be distinctions in language emotionality.

Thus, generally, ethnic differences had a stronger impact on love styles than linguistic variation. Concretely, the results showed that bilinguals were more agapic and more erotic than monolinguals, which means that the minority group is more passionate, romantic and self-sacrificing in an intimate relationship. Eros is a good base for sincere and warm relationships. Taking into consideration a previous finding stating that Agape is in a positive relationship with Neuroticism (White, Hendrick \& Hendrick, 2004), a cautious inference should be made. It seems that Agape has positive outcomes in a relationship just in cases when it is not very intensively present in the love profile. In this sense, the minority group has a rather idealistic view of love with a tendency to put their partner's welfare above theirs.

Another explanation here is that the romantic partnership is ruled by Agape, which means that there is an imbalance between the two partners' power relations: one side is giving up everything for the other and is exploited and manipulated covertly in a physical, psychological, material or emotional manner by the other. It may be that in times of harmony and satisfaction on both sides, Eros rises and a passionate feeling takes control over the relationship.

Agape and Eros were found in bilinguals' both first and second language as strongly protuberant styles, when compared to monolinguals. So there is an overlapping, matching pattern in the minority group's dominant language and their second language regarding love styles when compared to the majority group.

The results of the bilingual group comparing their first and second language showed a different pattern of styles: at the level of a tendency towards significance they were more manic and strogic in Hungarian, their dominant language than in their second language.

The Mania love style is often considered to be a symptom of love, but from another angle it is seen as a possessive and thus harmful and dangerous style. Previous research (White, Hendrick \& Hendrick, 2004) found that therapists interpret this style of dependent, preoccupied intimate behavior as pointing to neurotic tendencies in the person expressing it.

In contrast, Storge is a very stable style, based on friendship and it is a good ground for building lasting relationships. This style can be characterized by companionate behavior, understanding of each other and commitment, with no intensive passion and fire in it.

It is very interesting that in the results these two styles emerged together, because in a way they stand on the two extreme ends of an imagined passion line. It might be the case here that in this sample Mania is taken to be the signal of true love, the token of deep affection. In addition to this, it is probable that after a period of time, when the relationship stands the test of time, it alters in the direction of a confidence-based relationship, so Storge takes over dominance.

On the other hand, another possibility is that these bilinguals start their relationships through friendship or see friendship as a base for all relationships. The Mania style might be activated when they perceive a threat to their relationship and an intensive fear of loss appears. In these cases they might shift to manic occupations and intrusive thoughts about their loved one.

These two styles emerged in the bilinguals' first language, showing that in this language they express these attitudes more dominantly than in their second language. The results of the research point towards the likelihood that in their first language these styles are present more strongly and more intensively.

One conclusion from these results is that the bilingual group's within-subjects are more emotional in their first language. This seems to support the Emotional Contexts of Learning theory (Harris, 
OF PSYCHOLOGY

IN THE $21^{\text {st }}$ CENTURY Volume 4, 2012

14

Berko Gleason \& Aycicegi, 2006) which says that the first language is acquired in a more emotional setting, in the context of developing attachment with parents and caregivers, through very intensive emotional experiences. As a result, it is emotionally charged at a deeper level. The fact that just slight differences were found here may be due to the fact that the bilingual participants were raised in a bilingual context, acquiring a minority language as a dominant one and learning the majority language as a second language often from childhood.

Importantly, we must note that monolingual and bilingual group differences point to the same styles in both languages. Eros and Agape were elected as dominant styles in both languages of the bilingual minority group compared to monolingual majority group. The second conclusion drawn from the results is that the bilingual group has uniform love styles across languages compared to other ethnic groups.

Future research could investigate a wider range of complex emotions, e.g. negative emotions and situations connected with two or more languages and make cultural comparisons within and between languages.

Research on love styles combined with other personality dimensions and viewed through the prism of bilingualism should be continued in Vojvodina. There is a lack of studies dealing with emotions in Hungarian and Serbian, with comparing bilingual and monolingual groups in this respect. In addition to this, there is a need for research oriented towards finding out how these two very different languages map one onto the other in the minds of Vojvodinian bilinguals.

\section{Conclusions}

In conclusion, we can say that it seems that every language and every culture possesses a more or less unique affective and emotional repertoire. If we take into consideration bilinguals' minds, it could be stated that they have an even more complex and somewhat different emotion lexicon than monolinguals.

From the research outcomes obtained, it can be inferred that in this study language accounts for less variance than culture, because when we varied culture - in the sense of ethnic group membership - we found more significant differences between the groups compared. It is a very interesting result that in the monolingual-bilingual condition the differences were found in bilinguals' both languages within just the same styles, so the language switch did not alter the love style in the minority group.

Additionally, in this work the first language is slightly more emotional and shows a different pattern of love attitudes than the second one.

One new assumption from this pattern of results is that living in a multiethnic context with two or more languages in everyday use can produce a very complex picture in emotional functioning: it can affect language emotionality and the love styles expressed. This way, romantic behavior can be altered in the way that at the end there are slight differences in the individuals' first- and second language emotional expression and behavior, but at the same time, when the same bilinguals are compared to other groups, stability is found, expressed through the same dominant romantic attitudes in both of their respective languages.

The findings have important implications for bilingual emotional functioning: in bilinguals there might be the same general intimate behavioral pattern and expectation set present in both of their languages, but additional tiny differences might turn up in their first- and second language emotional repertoire, which can affect their behavior. Thus, being in their first- or second language mode can change the prospects of a relationship.

This research supports the broad notion that in dealing with the psychology of love and emotions it is important to take into account linguistic and cultural effects on intimate behavior.

\section{Acknowledgements}

This research was supported by the University of Novi Sad, Hungarian Teacher Training Faculty and the Ministry of Education and Science in Serbia, project number III 47013, with the title A magyar nyelv a többnyelvű Vajdaságban, a korszerủ európai régiómodellben. 
We would like to thank Susan Hendrick for providing us with the Love Attitudes Scale -Short Volume 4, 2012

Form and giving the permission to translate the scale.

\section{References}

Choo, P., Levine, T., \& Hatfield, E. (1996). Gender, Love Schemas, and Reactions to Romantic Break-ups. In: Crandall, R. (Ed.). Handbook of gender research, special issue, 143-160.

Eilola, T. M., Havelka, J., \& Sharma, D. (2007). Emotional activation in the first and second language. Cognition and Emotion, 21 (5), 1064-1076.

Harris, L. C., Berko Gleason, J., \& Aycicegi, A. (2006). When is a First Language More Emotional? Psychophysiological Evidence from Bilingual Speakers. In: Pavlenko, A. (Ed.). Bilingual Minds. Clevedon, Buffalo, Toronto: Multilingual Matters Ltd.

Hatfield, L. E., Bensman, L., \& Rapson, L. R. (2011). A brief history of social psychologists' attempts to measure passionate love. Journal of Personality and Social Psychology, 1-39. Retrieved 01/09/2012, from http://www.elainehatfield.com/122.pdf

Hatfield, E., Rapson, R. L., \& Martel, L. D. (In press). Passionate Love. In: Kitayama, S., \& Cohen, D. (Eds.). Handbook of Cultural Psychology. New York: Guilford Press., Retrieved 02/09/2012, from http://www. elainehatfield.com/ch78.pdf

Hendrick, C., \& Hendrick, S. (1986). A theory and method of love. Journal of Personality and Social Psychology, $50(2), 392-402$.

Hendrick, C., Hendrick, S., \& Dicke, A. (1998). The Love Attitudes Scale: Short Form. Journal of Social and Personal Relationships, 15, 147-159.

Hendrick, C., \& Hendrick, S. S. (2006). Styles of romantic love. In: Sternberg, R. J. \& Weis, K. (Eds.). The New Psychology of Love, New Haven, London: Yale University Press.

Mesquita, B., \& Frijda, N. H. (1992). Cultural Variations in Emotions: A Review. Psychological Bulletin, 112 (2), 179-204.

Navracsics, J. (2007). A kétnyelvü mentális lexikon. Budapest: Balassi Kiadó.

Neto, F. (2007). Love Styles: A Cross-Cultural Study of British, Indian, and Portuguese College Students. Journal of Comparative Family Studies, 38 (2), 239-254.

Pavlenko, A. (2005). Emotions and multilingualism. New York: Cambridge University Press.

Sachdev, I. \& Bourhis, R. Y. (1991). Power and Status Differentials in Minority and Majority Group Relations. European Journal of Social Psychology, 21, 1-24.

Schmitt, P. D. (2006). Evolutionary and Cross-Cultural Perspectives on Love: The Influence of Gender, Personality, and Local Ecology on Emotional Investment in Romantic Relationships. In: Sternberg, R. J. \& Weis, K. (Eds.). The New Psychology of Love. New Haven, London: Yale University Press.

White, J. K., Hendrick, S. S., \& Hendrick, C. (2004). Big five personality variables and relationship constructs. Personality and Individual Differences, 37, 1519-1530.

Advised by Stanislava Yordanova Stoyanova, South-West University "Neofit Rilski”, Bulgaria

Received: September 07, 2012

Accepted: October 16, 2012 